\title{
Analysis for Regional Differences and Influence Factor of Rural Income in China
}

\author{
Jinyu Chen, Wenxiu Zhang \\ College of Economic and Management, Sichuan University of Agriculture, Chengdu, China \\ Email: jinyucjy@163.com
}

Received May 2, 2012; revised June 2, 2012; accepted June 13, 2012

\begin{abstract}
The purpose of the present study is to analyze the space division characteristics and trends of the income gap between the rural resident in China using a statistical method, which based on the provincial panel rural resident's income series plan data from 1978 to 2008. The results of the study suggest that the east regional has the largest income disparity, the west has the second place, and central has minimum income gap. At last, the regression model was build based on Cobb-Douglas production function by combining the conversion factors and the influence of urbanization area. And the validity of the models was also demonstrated by regression analysis using 30 provincial or region's panel data.
\end{abstract}

Keywords: Cobb-Douglas; Regional Analysis; Rural Income; Statistical Methods

\section{Introduction}

Nowadays, our China has entered a well-off society with rapid development of national economy and the income of urban and rural residents greatly raised after 32 years of reform and opening. However, there has very big disparity in rural regional economy development level with growth of the economy. Due to the imbalance of regional economic development, the income gap inevitable derived in rural, so that the vast rural residents can not equal to share the benefits of economic growth. Rural residents' income is the biggest concern of the farmers, the "three issues concerning farmers" is virtually the core issue. Empirical studies our country rural regional gap and the income of the residents of the influential factors were analyzed for the government establish related policy, effectively achieve the farmers' income, narrowing the income gap between the areas, and have very important practical significance. Since the 1990s, many scholars in China for the actual situation in our country, in succession to our country income inequality problem carried on a series of research. They also include some scholars from different Angle to our country rural income gap of residents of the research, for example, Zhang [1] and Xue [2] through to the sample data, the empirical analysis to our country rural residents' income and the present condition of the income distribution, and the difference of the forming reasons for the differences have been deeply studies. Wan [3] also puts forward a framework of decomposition inequality, on the basis of the quantitative analysis in rural areas in China between the sources of income ine- quality. In the midwest farmer income difference for comparative studies, at the same time, the influence factors of the analysis that the amount of salary income has become a farmer income and the difference of the influence factors [4]. In fact, affect China's rural residents income inequality are various factors. For example, Meng and $\mathrm{Wu}$ [5], the research of the difference that endowment the rural regional income difference, but Wan [3] of the research is think geography and capital investment differences influence is China's rural resident's income inequality is the most important factor. In previous studies, most research results showed that China's rural regional income inequality on the rise and widening income gap is the reason for the uneven development of the non-agricultural industries. For the rural non-agricultural industries, on the one hand, as Yuan [6], the study points out, the non-agricultural industries as a major source of increasing farmers' income has been established and the position and consolidating, increasing the income of farmer's ability to contribute there is an obvious trend increase. On the other hand, the rural non-agricultural employment unequal opportunity brought about by the regional economic development is not balanced and gradually become decided to rural regional income disparity degree of the dominant factors of regret of be, how to influence non-agriculturalization of rural residents' income as the important factor into the mathematical model, so that from the point of view of measurement for empirical research, have been reported in the literature. This paper studies with the provincial panel statistical data, the empirical analysis since China's reform and opening in the 
east west three big economic zone internal and nationwide rural regional income gap, and reveals the income gap between rural the space distribution features and changes with time trend at the same time, this paper also will be on the analysis of the influence of the main factors of rural residents' income building regression model based on the characteristics of the regression model is introduced in the model in the conversion degree and urbanization coefficient, from the point of view of the measurement analysis to study in a rural urbanization factors on non-agriculturalization of factors and rural residents of the income distribution effects, this kind of influence in fact also reflects on the rural area of the influence of income gap.

\section{China's Rural Residents of the Gap between the Distribution Features and Trends}

\subsection{Measure Index Selection and Data Sources}

Most of the Gini coefficient is to measure the distribution of income inequality in the existing literature. And the Gini coefficient is the advantage of can be used as the degree of polarization between the rich and the criterion. In our country, the gap between rich and poor is approaching the red lines already is social allow undisputable fact. The Gini coefficient has some shortcomings: First, the Gini coefficient, many of the calculation method, not a unified formula of the second, Gini coefficient is susceptible to the effects of the income group in the value of the specific calculation difference [2].

Because of this study is to investigate the rural residents in China on the income gap between the space distribution and the tendency of changes over time, so just described in statistical data of discrete coefficients as discrete degree of the gap between the measure indexes can achieve the purpose of the research. A region the income of the residents in the area is in fact the difference degree resident's income distribution of discrete degree. In practical application, usually through variance and standard deviation as discrete degree of measure value but variance and standard deviation can only reflect the absolute value of the dispersion degree of statistical data, and the specific data by the size of the original variables itself on the level of influence, on the other hand also depends on the use of measurement. In order to eliminate the statistical variable values for level or measuring unit of different degree measure the influence of discrete values, need to use discrete coefficients [6] the discrete coefficients for different groups will statistical data of discrete degree discrete coefficients can compare simply by the sample data with the standard deviation of average than calculation and Gini coefficient, compared with that by using the advantages of discrete coefficient calculation method is single-minded, easy to use, easy to understand, and simple calculation is reasonable. This paper analyzes our country rural area for income inequality data from the all China statistical yearbook published between 1978 and 2008 provincial panel of the original statistical data.

\subsection{The Income Gap of Residents, Distribution Characteristics and Trends}

In order to further analysis nationwide and in east west three economic zone of rural resident's income differences within the distribution and change trend, using the China Statistical Yearbook published each period of each area per capita net income of rural households the statistical data of the rural area calculation reflect income disparity degree of discrete coefficient value, the results listed in Table 1.

Worth that China statistical yearbook of 1978-1990, 1981-1984, 1986-1989 in the region about rural households of per capita net income of statistical data in addition, still lack data in 1991 and 1991, according to the adjacent years of data, using the Newton (Newton) interpolation formula added 1991 data, which again 1991 income distribution calculated the discrete coefficient values.

From Table 1 we can found that the bigger of the discrete coefficients in income distribution, the bigger of the income gap, and vice versa.

Table 1. China's rural per capita net income of regional distribution of discrete coefficients*.

\begin{tabular}{|c|c|c|c|c|}
\hline Year & Eastern & Central & Western & Nationwide \\
\hline 1978 & 0.34 & 0.23 & 0.23 & 0.33 \\
\hline 1980 & 0.26 & 0.14 & 0.10 & 0.27 \\
\hline 1985 & 0.26 & 0.07 & 0.11 & 0.21 \\
\hline 1990 & 0.35 & 0.14 & 0.14 & 0.39 \\
\hline 1991 & 0.35 & 0.16 & 0.15 & 0.41 \\
\hline 1992 & 0.35 & 0.17 & 0.16 & 0.43 \\
\hline 1993 & 0.36 & 0.13 & 0.15 & 0.46 \\
\hline 1994 & 0.34 & 0.15 & 0.12 & 0.45 \\
\hline 1995 & 0.34 & 0.13 & 0.13 & 0.46 \\
\hline 1996 & 0.29 & 0.12 & 0.13 & 0.42 \\
\hline 1997 & 0.30 & 0.10 & 0.17 & 0.42 \\
\hline 1998 & 0.28 & 0.09 & 0.15 & 0.40 \\
\hline 1999 & 0.28 & 0.08 & 0.16 & 0.41 \\
\hline 2000 & 0.29 & 0.06 & 0.14 & 0.43 \\
\hline 2001 & 0.29 & 0.06 & 0.13 & 0.44 \\
\hline 2002 & 0.30 & 0.01 & 0.13 & 0.44 \\
\hline 2003 & 0.30 & 0.06 & 0.13 & 0.44 \\
\hline 2004 & 0.29 & 0.07 & 0.14 & 0.42 \\
\hline 2005 & 0.31 & 0.07 & 0.15 & 0.45 \\
\hline 2006 & 0.34 & 0.06 & 0.15 & 0.45 \\
\hline 2007 & 0.31 & 0.05 & 0.16 & 0.43 \\
\hline 2008 & 0.31 & 0.06 & 0.17 & 0.42 \\
\hline
\end{tabular}

Note: The data from China Statistical Yearbook (1996-2009). 
1) From the income gap between the space distribution look, the east area of the income distribution of discrete coefficient most, the western is the second smallest, and middle belt minimum, shows that the Chinese economy developed eastern economic zone rural residents income gap is the largest, and the west is the second smallest, and the income gap between the central and the minimum a result and at the beginning of this century Zhang [1] through the analysis of the income of Gini coefficient is the same results nationwide and the income distribution of discrete coefficients of east west high in any economic zone, indicates that the nation within the scope of the income gap between east west than in any economic zone of internal income gap within national rural income gap of residents more than the cause of the local area in the west of east of internal regions all the development of the rural economy has area this similarity including resource endowment similarity of similar geography.

2) From the time series on look, whether in the western region, or nationwide had a common characteristics, that is the first several years of reform and opening, the income distribution of discrete coefficients have a short-term drop process, explained this years China's rural income gap of residents experienced a short-term this process of shrinking about from close to the mid 1980s began, the income gap between rural residents began to expand from the overall perspective, our country rural area of the gap between the change of the features are clear from the last century because of 1978 to the 80 s, our country rural income gap of residents have experienced first to widen the process of narrow, so the following discussion from the 1990s to the east zone, from 1990 to 2008, the change of discrete coefficients can be divided into three stages. Because our country is known for her massive land, the vast rural areas are common location distributions and resources endowment imbalance, coupled with countries don't balance development policy and other reasons, China's rural areas will naturally formed differences in the levels of economic development, especially the more developed eastern region and the western underdeveloped region this difference between the more obvious this difference is, the bigger the is different regional income disparity among rural residents is bigger also, and thus opened the nationwide rural income gap of residents in order to address this, this article will east central rural residents' per capita and the west as a comparison, as shown in Table 2.

From Table 2, it was found that the China's eastern, western in rural residents income difference was significant, especially the gap between the western and eastern. From the time sequence, the gap was gradually expanded between the western region and eastern region from 1978. After 1990s, the highly gap gradually become stable, and its change trend similar to the discrete coefficients of
Table 2. China's eastern, central area per capita net income of rural resident's vs. the western area is in the west area*

\begin{tabular}{cccccc}
\hline Year & 1978 & 1980 & 1985 & 1990 & 1995 \\
\hline Eastern & 1.36 & 1.47 & 1.65 & 1.77 & 2.10 \\
Central & 1.04 & 1.12 & 1.18 & 1.16 & 1.32 \\
Year & 2000 & 2005 & 2006 & 2007 & 2008 \\
Eastern & 2.13 & 2.18 & 2.20 & 2.13 & 2.16 \\
Central & 1.27 & 1.29 & 1.30 & 1.33 & 1.29 \\
\hline
\end{tabular}

Note: The data from China Statistical Yearbook (1996-2009).

nationwide in Table 1. So, in China's eastern, western rural income gap of residents, especially in the western region of the income gap between rural residents, this led to nationwide since the 1990s. Obviously, narrowing the regional gap between rural the income of the residents, especially the western rural income gap of residents, for narrowing the national rural regional distribution of income gap is of great significance.

\section{China's Rural Income Gap of Residents Effect Factors of the Regression Analysis}

\subsection{Consideration of Mode}

The income of a region in rural residents' affected by various factors. These influence factors in different areas of the difference between the regions rural residents income gap. Therefore, through the income of the residents of rural analysis of influence factors, this can realize to the factor analysis in rural residents of the influence of income gap.

In the former research, usually reference Cobb-Douglas production function, the substance capital and human capital stock as the main factors affecting income. Herein, we try to using Cobb-Douglas production function to develop and introduce conversion degree as a variable index to quantitatively the empirical analysis the income of the residents of rural non-agriculturalization of influence. Additionally, a region of human capital is the key factor influence per capita income. In the existing literature, the population of the fixed number of year by education usually is as a measure of human capital stock index. However, some research indicated it is not evident on rural residents' income's influence if only consider residents affected by the education level. For example, Xin and Wang [7] by the education level of recent farmers and farmers' income of the relationship between the empirical research points out, though the long run by the education level of farmers' incomes have role in promoting improve, but the impact is weak, and no decisive role. Wang and $\mathrm{Li}$ [8] earlier research thought that the present education investment and even China agriculture development does not exist between obvious causal relationship. Therefore, the human capital stock needed to give a 
deeper level of meaning.

Because of people's intelligence play by the environment factors, such as rural areas of the human condition is the impact the quality of human capital is an important external factors, different regions and different shape of culture, and the concept, farmers in the cultural differences in outlook will cause its accept and learning advanced production technology of the difference, which affect the quality of the human capital. Normally, the surrounding rural town than remote mountain area should be has more superior humane conditions, thus more help to the rural human capital is advanced. The form of awareness and skill, the stronger in the interpersonal and the spread of knowledge and information. Consider these factors, the paper will be a rural area labor education level and the level of urbanization by combining into a new human capital stock index, from further level consider human capital for the farmers the influence of the village residents' income.

\subsection{The Considering of Regression Model}

Herein, according to Cobb-Douglas production function, the rural residents' income and its main influence factors could be shown using following function:

$$
Y_{i}=A K_{i}^{\alpha} H_{i}^{\beta} Z_{i}^{\gamma}
$$

Herein, the subscript $\mathrm{i}$ represents a province or a region. $Y_{i}, K_{i}, H_{i}$ and $Z_{i}$ are rural per capita net income per capita, material capital stock, human capital and non-agriculturalization degree; A is the technical level. $\alpha, \beta$ and $\gamma$ are parameters. So, the Equation (1) could be revised:

$$
\ln Y_{i}=\ln A+\alpha \ln K_{i}+\beta \ln H_{i}+\gamma \ln Z_{i}
$$

\subsection{Variables Index}

\subsubsection{The Material Capital Stock Index $K$}

This article with the provinces or region fixed assets investment divided by total rural population in the area as the people in the rural areas total material capital stock.

\subsubsection{Human Capital Storage $\boldsymbol{H}$}

Most of the literature of the human capital formation to education investment, for example, Ma and Zhang [9] with more than six years old by the education of fixed number of year of average population to say human capital stock. Chen Jie [10] according to a labor accepts different degree education area population estimates for the proportion of human capital. Herein, consider education and town environment on the dual effects of human capital, the human capital stock could be showed as following Equation:

$$
H=\lambda Q
$$

$\lambda$ and $Q$ are urbanization coefficient and education factors. And then, the education factors could be revised
Equation (4) according to Chen Jie (2007):

$$
Q=\sum_{j=1}^{6} q_{j} h_{j}
$$

$q_{j}$ is the proportion of the labor force. $h_{j}$ is conversion coefficients and the primary education is 1 , junior high school is 1.5 , high school is 2 ; technical secondary school is 2.5 , college degree and above is 4 and illiteracy is 0.5 .

\subsubsection{Conversion Degree $Z$}

Herein, the degree of non-agriculturalization will be defined as a percentage of the agricultural, forestry, animal husbandry and fishery workers to all of the employees.

$$
\begin{aligned}
Z= & \frac{N(\text { total })-N(\text { agricultural, forestry and animal })}{N(\text { total })} \\
& \times 100 \%
\end{aligned}
$$

\subsubsection{Data Source of Regression Analysis}

Regression analysis of the sample data, including provinces (including autonomous regions and municipalities) per capita net income of rural households, the total investment of fixed assets, rural areas population, rural residents of family education, labor force of the urban population proportion of the total population, rural workers number and rural ecological-economic from industry personnel number.

Considering the between the integrity of the statistical data in recent years and can obtain sex, in addition to the proportion of the total population of the urban population comes from the China statistics Yearbook published the 2005 census data outside, the rest data are all derived from the 2006 edition of the rural China statistical yearbook male cloth of the 2005 census data. Due to the lack of the Tibet autonomous region in 2005, total investment of rural fixed assets statistical data, this paper will except in Tibet outside of the 30 provinces (autonomous regions and municipalities). According to the above data will be above all variables in the proper arrangement the definition of index, summarized in Table 3.

\subsection{The Results of Regression Analysis}

According to the regression model of linear expression (2) of multiple linear regression and the results summarized in Table 4.

Multiple linear regression model of significant inspection including regression coefficient of significant test and regression equation of significant inspection was listed in Table 4. The regression coefficients t showed that the per capita material capital stock, stock of human capital and degree of non-agricultural have significant affect to per capita net income of rural residents. At the same time, the $\mathrm{F}$ inspection, it is known that the linear Equation (2) by 
Table 3. The provincial panel data of regression analysis.

\begin{tabular}{ccccccc}
\hline Region & PN & $K$ & $Q$ & $\lambda$ & $H$ & Con $(\%)$ \\
\hline Beijing & 7346 & 6071 & 1.82 & 0.84 & 1.52 & 68.15 \\
Tianjin & 5580 & 3301 & 1.55 & 0.75 & 1.16 & 55.4 \\
Hebei & 3482 & 1534 & 1.50 & 0.38 & 0.57 & 44.06 \\
Shanxi & 2891 & 680 & 1.45 & 0.42 & 0.61 & 41.29 \\
Neimeng & 2989 & 657 & 1.38 & 0.47 & 0.65 & 23.39 \\
Liaoning & 3690 & 2290 & 1.51 & 0.59 & 0.89 & 38.36 \\
Jilin & 3264 & 1101 & 1.38 & 0.53 & 0.73 & 26.72 \\
Heilongjiang & 3221 & 814 & 1.44 & 0.53 & 0.76 & 26.58 \\
Shanghai & 8248 & 9199 & 1.74 & 0.89 & 1.55 & 75.93 \\
Jiangsu & 5276 & 3657 & 1.46 & 0.50 & 0.73 & 60.25 \\
Zhejiang & 6660 & 4578 & 1.41 & 0.56 & 0.79 & 65.76 \\
Anhui & 2641 & 760 & 1.34 & 0.35 & 0.48 & 39.89 \\
Fujian & 4450 & 1344 & 1.37 & 0.47 & 0.65 & 47.28 \\
Jiangxi & 3129 & 830 & 1.37 & 0.37 & 0.51 & 41.97 \\
Shandong & 3931 & 2891 & 1.50 & 0.45 & 0.68 & 45.91 \\
Henan & 2871 & 1063 & 1.44 & 0.31 & 0.44 & 34.19 \\
Hubei & 3099 & 724 & 1.40 & 0.43 & 0.61 & 42.99 \\
Hunan & 3118 & 776 & 1.42 & 0.38 & 0.52 & 34.40 \\
Guangdong & 4691 & 1686 & 1.47 & 0.61 & 0.89 & 50.36 \\
Guangxi & 2495 & 435 & 1.46 & 0.34 & 0.49 & 33.94 \\
Hainan & 3004 & 531 & 1.44 & 0.45 & 0.65 & 24.45 \\
Chongqing & 2809 & 642 & 1.32 & 0.45 & 0.59 & 42.43 \\
Sichuan & 2803 & 860 & 1.34 & 0.33 & 0.44 & 39.03 \\
Guizhou & 1877 & 302 & 1.21 & 0.27 & 0.33 & 34.44 \\
Yunnan & 2042 & 519 & 1.19 & 0.29 & 0.35 & 17.59 \\
Shanxi & 2053 & 506 & 1.41 & 0.38 & 0.53 & 33.95 \\
Gansu & 1980 & 406 & 1.27 & 0.30 & 0.38 & 29.78 \\
Qinghai & 2152 & 532 & 1.11 & 0.39 & 0.44 & 30.81 \\
Ningxia & 2509 & 1477 & 1.18 & 0.42 & 0.49 & 33.68 \\
Xinjiang & 2483 & 1305 & 1.33 & 0.37 & 0.50 & 14.81 \\
\hline Hian & & & & & &
\end{tabular}

Note: PN: Per net income (RMB).

Table 4. The results of regression analysis based on 30 provinces or region.

\begin{tabular}{cccccccc}
\hline \multicolumn{5}{c}{ Regression coefficient } & $\mathrm{F}$ & $\mathrm{R}$ & $\mathrm{R}^{2}$ \\
\cline { 1 - 5 } $\ln \mathrm{A}$ & $\alpha$ & $\beta$ & $\gamma$ & & & \\
\hline 6.27 & 0.18 & 0.48 & 0.21 & & & \\
$18.31^{*}$ & $4.21^{*}$ & $5.58^{*}$ & $4.04^{*}$ & & & & \\
\hline
\end{tabular}

Note: $\mathrm{t}$ test values of the regression coefficients in the brackets. " above $0.5 \%,{ }^{* *}$ above $0.1 \%$.

the regression equation of the expression is significant, which has verified regression model type (1) is correct. The material capital, human capital and the degree of nonagriculturalization of rural residents' income have significant positive effect. The result of Table 4 indicated that the elasticity coefficient of human capital stock was significantly higher than other two explanatory variables $\alpha$ and $\gamma$. It showed that the human capital accumulation to the contribution of rural residents' income is higher than the other two explain the contribution of variables. The human capital accumulation to rural residents' income contribution represents the rural labor force by education level and the level of urbanization in the comprehensive effect. And some other research of the comparison results in this paper, the urbanization factor, the introduction of the human capital to did raise the rural residents, the contribution rate of income, which has verified based on human capital stock of urbanization factor into the if, that is, with the area to raise the level of urbanization, can improve the rural areas of the human condition and improve the quality of rural labor force and high quality of rural human capital formation is an intangible investment.

\section{Conclusions}

According to this article of China's rural residents' income of the regional differences and effect factors of the empirical results, we can draw the main conclusions are as follows:

1) China's rural income gap of residents, the space distribution features of performance: the eastern economic zone rural resident's income gap is the largest, the west is the second smallest, and central minimum. Compared with the local region, there has a bigger income gap of nationwide rural than the eastern and western.

2) Our country rural income gaps of residents have the change tendency of the phases since the reform and open. Although different rural area through different stages of the change of the income gap, but there is a common characteristics: that is whether the eastern, central and western areas or national scope, the beginning of reform and opening up a few years, rural income gap of residents have experienced a short-term narrowing of the process, then began to expand the income gap. Across the country, from 1990-2008, this paragraph of a long period, the income gap between rural residents while high and low, but little variations, the income gap widening rural residents have been running high.

3) In China's eastern, western, obvious gap since reform and opening up, the gap with time and the trend of rural residents nationwide the income gap between the change trend, the basic consensus, which show that a fact, China's eastern between western rural income gap of residents are caused by the national rural high income gap of residents of the main causes.

4) Using regression model, the empirical analysis shows that: firstly, the degree of non-agriculturalization of rural resident income are significant positive role, the development of the non-agricultural industries has become an important means of rural residents' income; the second, the regression model can significantly enhance human 
capital to the contribution of rural residents income; lastly, aim to speed up the major and medium city as the leading urbanization construction, not only to narrow the gap between urban and rural areas, and to improve the rural labor quality, promote the agricultural production and peasants' income also has important practical significance.

\section{Acknowledgements}

The authors gratefully acknowledge the National Social Science Fund (No.08XJY011) and Sichuan Provincial Social Science Key Projects Fund (No. 09SA096) for financial support.

\section{REFERENCES}

[1] X. H. Zhang, “China’s Rural Resident's Income Distribution Empirical Description and Analysis of the Change," Chinese Rural Economy, No. 6, 2001, pp. 12-18.

[2] Y. F. Xue, “China's Rural the Distribution of Income Inequality and Its Regional Differences,” Chinese Rural Economy, No. 5, 2005, pp. 26-34.

[3] X. F. Xin, F. Qin and X. Q. Wang, “The Midwest Farmer Income and the Difference of the Influence Factors Analysis," Chinese Rural Economy, No. 2, 2008, pp. 40-52.
[4] G. Wan, "Accounting for Income Inequality in Rural China Regression-Based Approach,” Journal of Comparative Economics, Vol. 32, No. 2, 2004, pp. 348-363. doi:10.1016/j.jce.2004.02.005

[5] X. Meng and H. X. Wu, "Household Income Determination and Regional Income Differential in Rural China," Asian Economic Journal, Vol. 12, No. 1, 1998, pp. 65-88. doi:10.1111/1467-8381.00052

[6] W. Yuan, "Statistics," Higher Education Press, Beijing, 2009.

[7] L. Xin and Y. H. Wang, "Farmers Education Level and Farmers' Income by the Relationship between the Empirical Researches,” Chinese Rural Economy, No. S1, 2007, pp. 93-100.

[8] X. Q. Wang and J. L. Li, “An Empirical Study on the Relation of Investment for Education and Agricultural Development," China Rural Survey, Vol. 58, No. 5, 2004, pp. 44-49.

[9] B. Ma and F. R. Zhang, "An Empirical Analysis of the Factors Affecting the Gap between Urban and Rural Residents," Chinese Rural Economy, No. 2, 2008, pp. 53-59.

[10] J. Chen, "A Structural Analysis of the Human Capital's Contribution to Economic Growth," The Journal of Quantitative \& Technical Economics, No. 8, 2007, pp. 60-69. 